\title{
Author Correction: Diversity and bioactive potential of culturable fungal endophytes of Dysosma versipellis; a rare medicinal plant endemic to China
}

\author{
Xiao-ming Tan ${ }^{1}$, Ya-qin Zhou ${ }^{2}$, Xiao-lei Zhou' ${ }^{2}$, Xiang-hua Xia ${ }^{2}$, Ying Wei ${ }^{2}$, Li-li He², Hong- \\ zhen Tang ${ }^{1} \&$ Li-ying Yu ${ }^{2}$
}

Correction to: Scientific Reports https://doi.org/10.1038/s41598-018-24313-2, published online 12 April 2018

The original version of this Article contained errors in the spelling of the authors Xiao-ming Tan, Ya-qin Zhou, Xiao-lei Zhou, Xiang-hua Xia, Li-li He, Hong-zhen Tang and Li-ying Yu which were incorrectly given as Xiaoming Tan, Yaqin Zhou, Xiaolei Zhou, Xianghua Xia, Lili He, Hongzhen Tang and Liyin Yu respectively.

These errors have now been corrected in the PDF and HTML versions of the Article, and in the accompanying Supplementary Information file.

(i) Open Access This article is licensed under a Creative Commons Attribution 4.0 International cc. License, which permits use, sharing, adaptation, distribution and reproduction in any medium or format, as long as you give appropriate credit to the original author(s) and the source, provide a link to the Creative Commons license, and indicate if changes were made. The images or other third party material in this article are included in the article's Creative Commons license, unless indicated otherwise in a credit line to the material. If material is not included in the article's Creative Commons license and your intended use is not permitted by statutory regulation or exceeds the permitted use, you will need to obtain permission directly from the copyright holder. To view a copy of this license, visit http://creativecommons.org/licenses/by/4.0/.

(c) The Author(s) 2018

${ }^{1}$ Guangxi University of Chinese Medicine, Nanning, 530200, China. ${ }^{2}$ Guangxi Botanical Garden of Medicinal Plant, Nanning, 530023, China. Correspondence and requests for materials should be addressed to X.-m.T. (email: txm1978@126.com)or H.-z.T. (email: hzhent2012@126.com) 